\title{
Design and implementation of a smart home system with two levels of security based on IoT technology
}

\author{
Mohammed Murad ${ }^{1}$, Oguz Bayat ${ }^{2}$, Hamzah M. Marhoon $^{3}$ \\ ${ }^{1,2}$ School of Engineering and Natural Science, Altinbas University, İstanbul, Turkey \\ ${ }^{3}$ Department of ComputerTechniques Engineering, Al-Esraa University College, Baghdad, Iraq
}

\begin{tabular}{ll}
\hline \hline Article Info & ABSTRACT \\
\cline { 2 - 2 } Article history: & $\begin{array}{l}\text { Besides the development of technology in recent years, there has been an } \\
\text { effective tendency to construct smart cities and homes. Whereas the smart } \\
\text { home control system components can be incorporated with the existing home } \\
\text { appliances to eliminate the need for human intervention, save electricity, } \\
\text { peceived May 24, } 2020 \\
\text { protect homes from accidents as well as the theft, and provide home residents } \\
\text { with comfort. This work comprises the utilising of the internet of things (IoT) } \\
\text { technology to build the proposed design for the smart home. The proposed } \\
\text { design includes many subsystems as well as several types of sensors, such as } \\
\text { the passive infrared (PIR) sensor, the gas sensor, the soil moisture sensor, the } \\
\text { water level sensor, the temperature sensor, the light dependent resistance } \\
\text { (LDR), and the flame sensor. Each sensor will be connected to the Arduino } \\
\text { Arduino }\end{array}$ \\
$\begin{array}{l}\text { Nano for the data processing purpose, after which the Arduino Nano will be } \\
\text { connected to the NodeMCU module via the digital pins to implement the IoT } \\
\text { IoT }\end{array}$ & $\begin{array}{l}\text { subsystem. The proposed system also includes a smart garage gate based on } \\
\text { Bluetooth HC-05 module with a specially programmed android app. }\end{array}$ \\
NodeMCU &
\end{tabular}

This is an open access article under the CC BY-SA license.

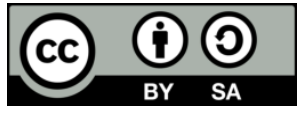

Corresponding Author:

Hamzah M. Marhoon

Department of Computer Techniques Engineering

Al-Esraa University College

Baghdad, Iraq

Email: hamzaalazawy33@yahoo.com

\section{INTRODUCTION}

In recent years, there has been a growing interest in smart home systems. Whereas the automated control of the appliances enables users to perform tasks before arriving at their home, in other words, there is no need for human intervention. The smart home control system offers an effective solution for assistive the disabled and elderly by utilising the mobile phone apps as a remote control or for monitoring purposes [1].

The construction of the automation systems for the offices, homes, companies, and other institutions has been increased on a daily basis with numerous advantages as well as specifications. Where, with the emergence of smart, easy-to-operate, as well as programmable controllers such as Arduino and Raspberry Pi, there has been a significant increase in the smart automation systems. The researchers, as well as manufacturers, are working to create the smart systems that protect the property from disasters and save energy through automatic operation of electrical appliances based on the need to operate only. Home Automation gives an individual ability to control things around the home remotely or automatically. The term of the home appliances means a device or instrument designed to perform a specific function, in particular an electrical instrument, for household use [1, 2].

Since a few years ago, the term Internet of Things (IoT) appeared and began to spread widely. This technology has been used in a wide field that includes smart homes, smart control, and even medical 
applications. This term is often used to refer to the growth in the network for connected devices, or "things", that are able to exchange data through a low bandwidth network. The connected devices support institutions to improve automation and performance, while at the same time may exhibiting the system to the security threats. So, institutions must, therefore, have a proper security strategy and solutions while deploying IoT within their infrastructure, thus would help them achieve their business objectives correctly [3-6]. The IoT system consists of many components which can be listed as follows:

a) Sensors and appliances, which are the elements of the device connectivity layer. These smart sensors are continuously accumulating the data from the environment and transmit the information to the next layer.

b) Gateway, IoT gateway controls the bidirectional data traffic among various networks and protocols. The second purpose of the gateway is to translate the difference in the network protocols and make certain interoperability of the connected appliances and sensors.

c) Cloud, IoT produces extensive data from appliances, applications, and users which has to be managed in an expedient way. IoT cloud provides tools to handle, process, manage, and store huge amount of data in real-time. Industries and services can easily access these data wirelessly and take decisive decisions when necessary.

d) User interface, User interfaces are the apparent and physical part of the IoT system which can be accessed by users, Figure 1 illustrates the general components for any IoT system.

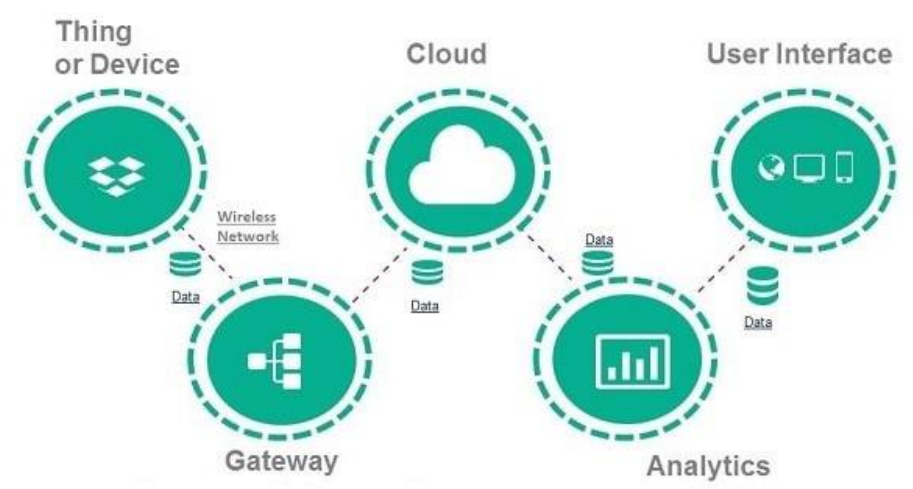

Figure 1. The architecture of the IoT system

In this work, the smart home system design will be proposed and will consist of a set of subsystems that can be listed as follows: the first part is two levels of security; the first level is based on the Passive Infrared (PIR) sensor which received the emitted infrared from the human body and the second level is based on the laser beam. The second part of the proposed system includes the automation as well as the safety system where it will be responsible for the detection of gas leakage, fire, low water tank level, monitor the temperature, and low water level in the garden soil. Also, in the toilet a gas sensor will be installed which is responsible for exploring the undesired smells, thereby operating the air evacuator and thus saving electrical energy as well as the increasing the operating life of the device. The two parts of the proposed system will be based on the IoT technology, as the homeowner will be able to remotely monitor his home via a local IP granted by the NodeMCU microcontroller which enabling the user to access the system's Graphical User Interface (GUI). The third and final part is the design of the smart garage gate, which will be opened/closed utilising a specially programmed app installed on the Android smartphone, allowing for the wireless control of the garage gate via Bluetooth technology. The paper is organised as follows: Section 2 illustrates the proposed system modules as well as sensors such that flame sensor, gas sensor, water level sensor, soil humidity sensor, temperature sensor, flame sensor, PIR sensor, Arduino Nano, HC-05 Bluetooth module, Arduino Mega, and NodeMCU module. Section 3 presents the necessary steps for the system design, implementation, working principle, and the obtained results after applying the practical test for the implemented design. Finally, Section 4 demonstrates the conclusion of the paper.

\section{SYSTEM HARDWARE}

In this part of the paper, the hardware and the components that will be utilised to build up the proposed smart home system such as the sensors and the other modules will be explained. 


\subsection{Arduino microcontroller}

Arduino is a single-board microcontroller that can be programmed utilising an open-source programming language called the Integrated Development Environment (IDE). The Arduino can be viewed as a small computer, in other words, the Arduino can be programmed to process input as well as output data between the device and peripheral components. In this work two types of the Arduino are utilised, the first one is the Arduino Mega which is based on the ATmega2560, as shown in Figure 2. The Arduino Mega comprises a 54 digital input/output pins (15 of them can be utilised to produce the analogue output via the PWM technique), 16 analogue inputs, 4 hardware serial ports, a $16 \mathrm{MHz}$ crystal oscillator, a USB connector, a power jack, ICSP header, and a restart button [7-10]. The second utilised microcontroller is the Arduino Nano board this type doesn't contain DC jack so that the power supply can be fed utilising a small USB port or can be directly through the VIN \& GND pins. The Arduino Nano contains a 14 digital input/output pins, 6 analogue input pins, and $16 \mathrm{MHz}$ CLK speed [11]. Figure 3 illustrates the Arduino Nano board with the configuration of the pins.

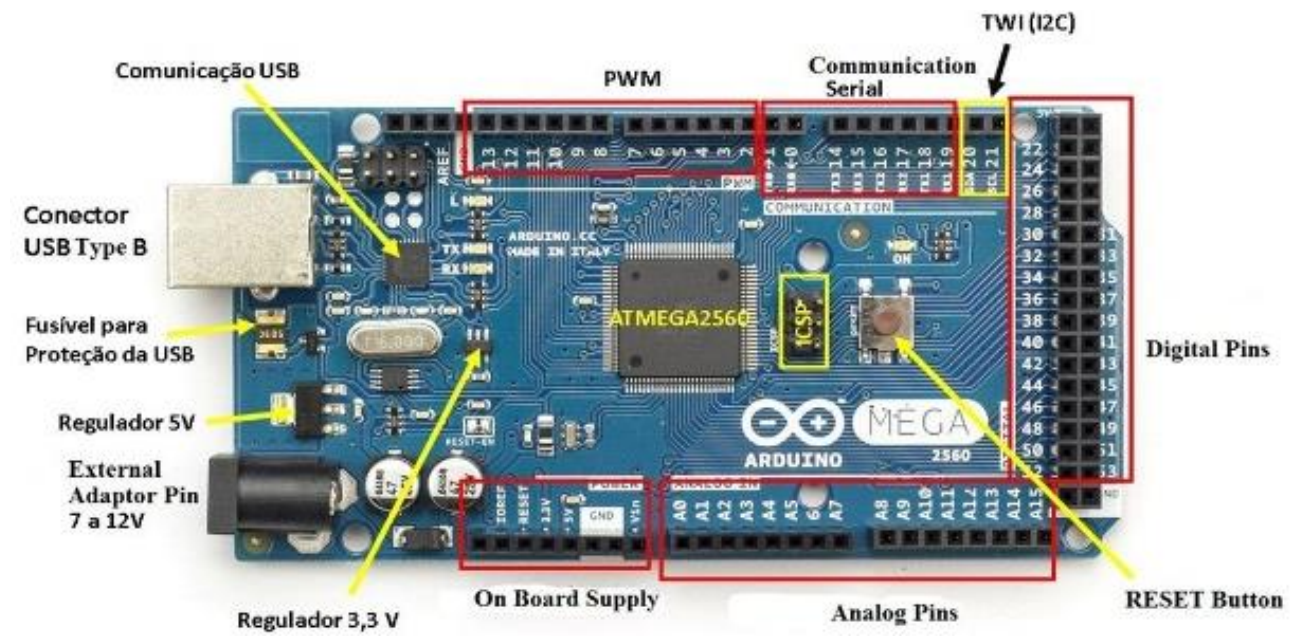

Figure 2. Arduino mega microcontroller

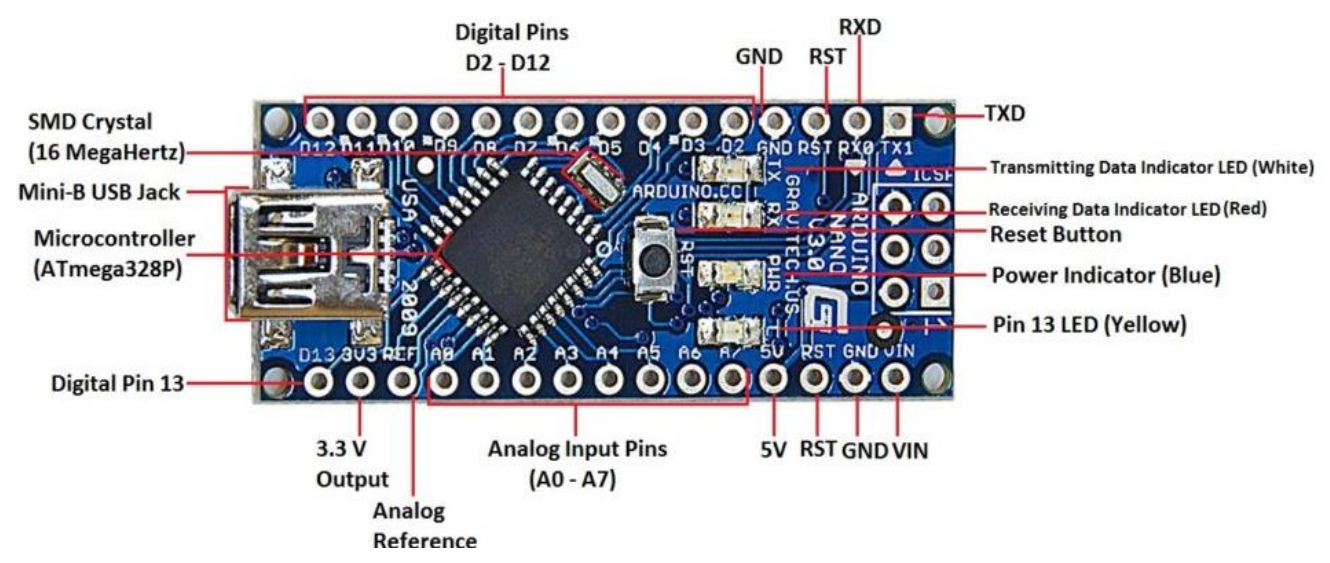

Figure 3. Arduino nano microcontroller

\subsection{NodeMCU microcontroller}

NodeMCU is a low-cost, open-source microcontroller board that supports the IoT technology. It included firmware running on the ESP8266 Wi-Fi System on Chip (SoC) from Espressif Systems and hardware based on the ESP-12 module. The NodeMCU uses the micro USB cable that makes it possible to run like the Arduino microcontroller board. Figure 4 illustrates the NodeMCU module with its pins configuration. This module has a high processing speed than Arduino and some other controllers, but the main drawback of this module is the containing of a single input analogue input pin [12-14]. 


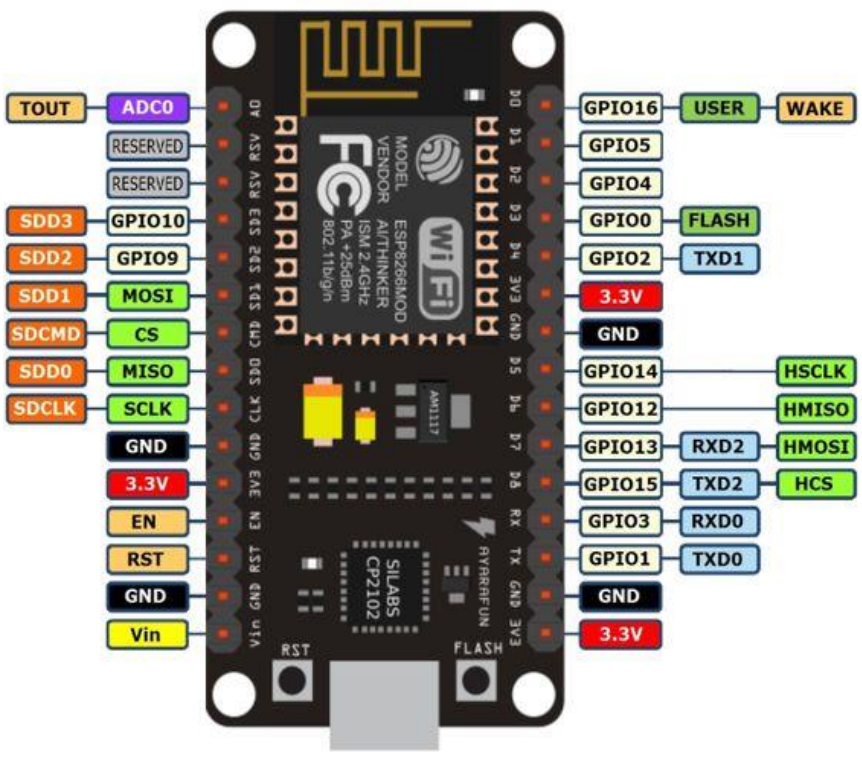

Figure 4. NodeMCU microcontroller board

\subsection{Flame sensor module}

The flame sensor module consists of a photodiode and operational amplifier used utilised to adjust the sensitivity, this sensor designed to detect the presence of the flame as well as the ordinary light which has a wavelength in the range of 760 to $1100 \mathrm{~nm}$, with a detection range up to $100 \mathrm{~cm}$. Generally, the module consists of four terminals, two of which are used for the sensor power supply (i.e. VCC\&GND), the third terminal for the analogue output, its output voltage increases with the increasing of the flame amount, and the left terminal is the digital output which indicates the HIGH output in the case of a flame being detected $[15,16]$. Figure 5 illustrates the flame sensor module and the sensor output voltage vs. the detection distance.

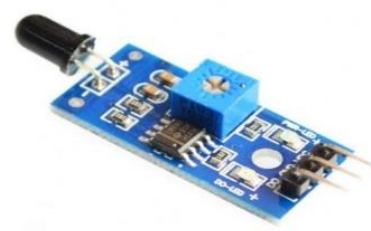

(a)

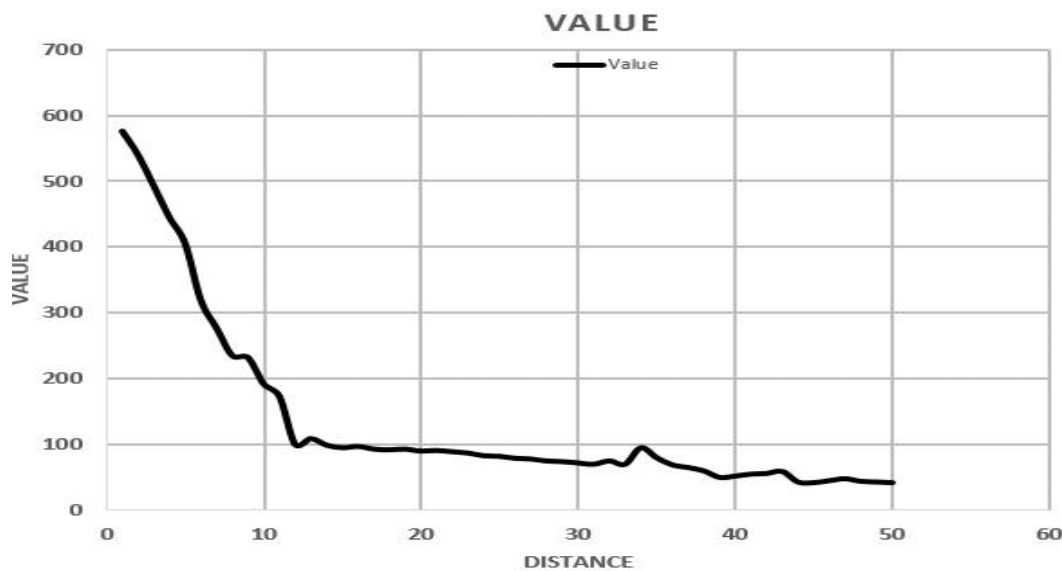

(b)

Figure 5. (a) Flame sensor module, and (b) Flame sensor value vs. detection distance

\subsection{Soil humidity sensor}

As shown in Figure 6, the soil moisture sensor consists of two probes that allow the current to pass through the soil and then obtain a resistance value. When the water is present, the soil will conduct more electricity and give low resistance, while in the case of dry soil, the flow of the electricity is poor so the resistance has a high value. The utilised microcontroller will compare the resistance value and, depending on the higher resistance, the water pump will be switched on $[17,18]$. 


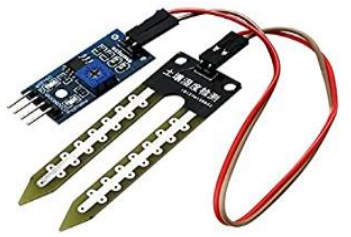

Figure 6. Soil moisture sensor module

\subsection{Passive infrared sensor}

The Passive Infrared (PIR) sensor designed to sense the movement dependent on the emitted infrared from the human body and the other living organisms. The PIR is composed of a pyroelectric sensor, which can recognise different levels of infrared radiation. The level of radiation will increase with the increase in the object's temperature when the human passes from the front of the PIR, the sensor will detect the human temperature and return a logic "1" from the sensor output pin $[19,20]$. To increase the detection range of the sensor, a hemispherical lens is used to collect radiation from different angles and direct it to the sensor as shown in Figure 7.
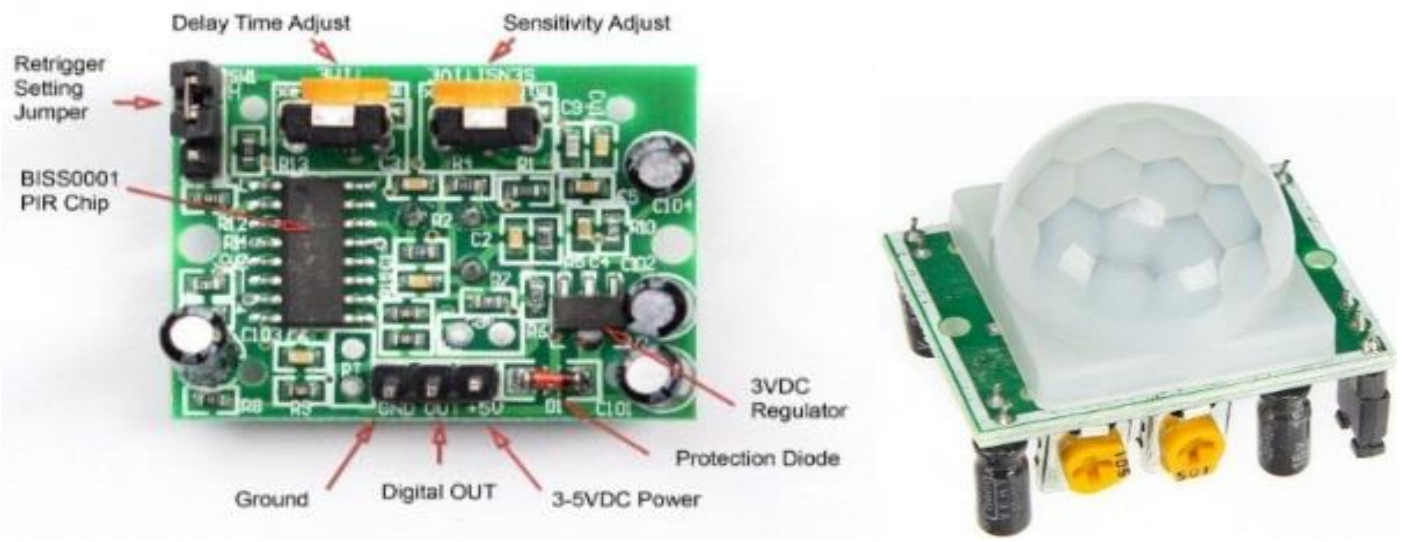

Figure 7. PIR sensor module

\subsection{MQ-05 gas sensor}

MQ-5 gas sensor is used for the applications of the gas leakage detection in both consumer and industrial systems. This sensor is proper for the detection of liquefied petroleum gas, natural gas, and coal gas. The working principle of the MQ-5 sensor module can be described in Figure 8. The heating coil " $\mathrm{H}$ " is associated with a $\mathrm{SnO} 2$ filament, in the presence of clean air, its resistance across the heating coil doesn't vary. But in case of combustible gas is present, the resistance of the $\mathrm{SnO} 2$ filament decreases, which results in a corresponding increase in output voltage pin of the sensor, this output voltage can be measured to indicate the concentration of any combustible gas [21, 22]. Figure 9 shows the MQ-8 gas sensor module with its pin configuration.
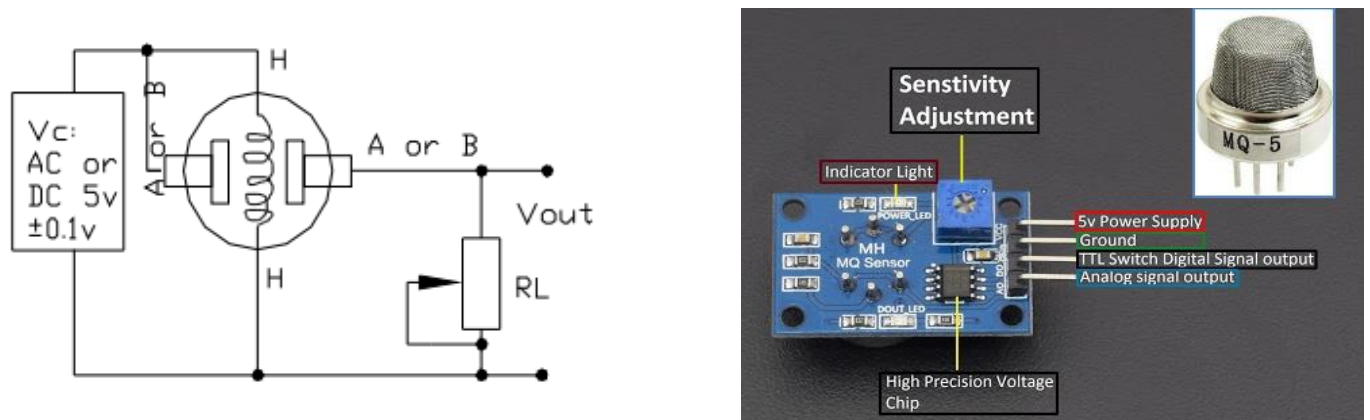

Figure 8. Internal structure of the MQ-5 gas sensor

Figure 9. MQ-5 gas sensor module 


\subsection{Servo motor}

The servo motor is an electrical component that can be utilised to push or rotate an object with high accuracy. The servo motor differed from the other motor types where it could rotate according to the required angles that can be obtained from the pulse length with the help of the microcontroller unit. In addition, the servo motor is characterised by a good torque and constant speed that is not affected by the change in load [23-25].

\section{SYSTEM DESIGN AND IMPLEMENTATION}

This section includes the necessary steps for the design of a smart home system with two levels of security based on IoT technology. This section also includes a presentation of the results obtained after the practical test for the proposed system has been applied.

\subsection{System design}

The proposed system consists of two main parts, the first part is a security system and the second part is an automation control system. The security system consists of the PIR sensor and the laser beam with Light Dependent Resistance (LDR). When the thief passes in front of the PIR sensor, the sensor analyses the infrared radiation that emitted from its body, then the Arduino Nano activating the alarm, Wi-Fi camera, and send logic " 1 " to the NodeMCU in order to display the alarming message on the GUI. Besides, when the thief cuts the directed laser beam to the LDR, the resistance value will increase and the Arduino Nano doing the same previous steps. The security system is powered by a control system based on the Arduino Mega, relay controller, and a $4 \times 4$ keypad, as shown in the connection diagram in Figure 10 . In order to turn ON/OFF the security as well as the automation system, a different password for both the ON and OFF states should be entered. In addition, a $16 \times 2$ liquid crystal display is also utilised to indicate that the system in the ON or OFF state, as illustrates in Figure 11.

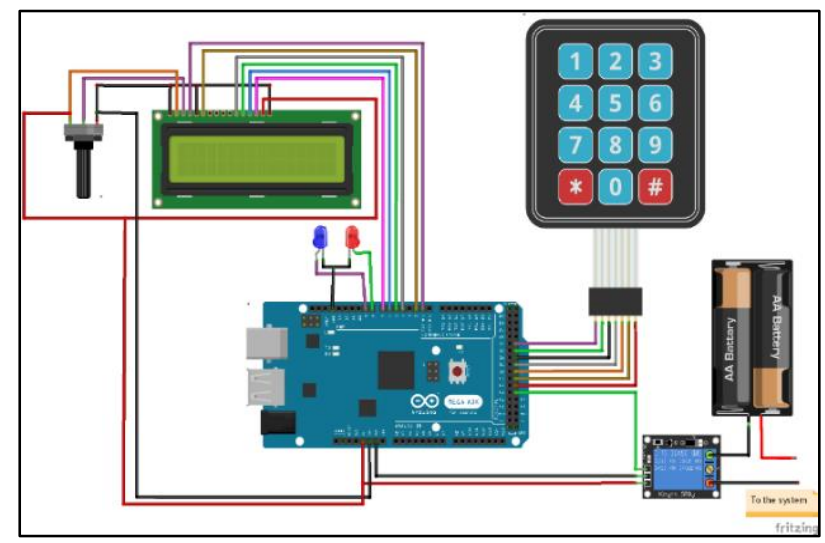

Figure 10. Connection diagram of the power control system

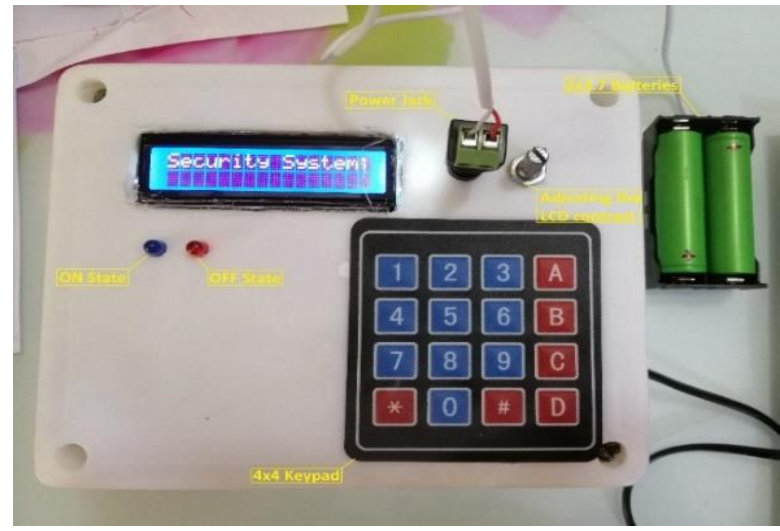

Figure 11. Implemented power control system 
The automation and control part based on the Arduino Nano microcontroller with many types of sensors, such as the two gas sensors, the flame sensor, the soil moisture sensor, LM 35 temperature sensor, and the water level sensor, the task of each sensor in this part is demonstrated in Table 1. In addition, the two parts of the proposed system are linked to the NodeMCU microcontroller, which supports the IoT technology, where the Arduino Nano read the sensors data and send logic " 1 " or " 0 " to the NodeMCU to display the necessary messages on the GUI, this method is utilised due to the limited analogue input pins of the NodeMCU as well as to provide the reliability to the proposed system, if one of the microcontrollers fail or damaged will not effects on the rest of the system. The homeowner can continuously monitor his home remotely via local IP address, enabling him to access the GUI which is programmed to monitor the home in different cases. The HC-05 Bluetooth with its compatible Android app and the servo motor is also utilised to remotely control the garage gate. The Android app was programmed through the MIT App Inventor platform, which was created by Google, and supervised by MIT University, which boils down to the easy-to-develop graphical programming blocks, as illustrated in Figure 12.

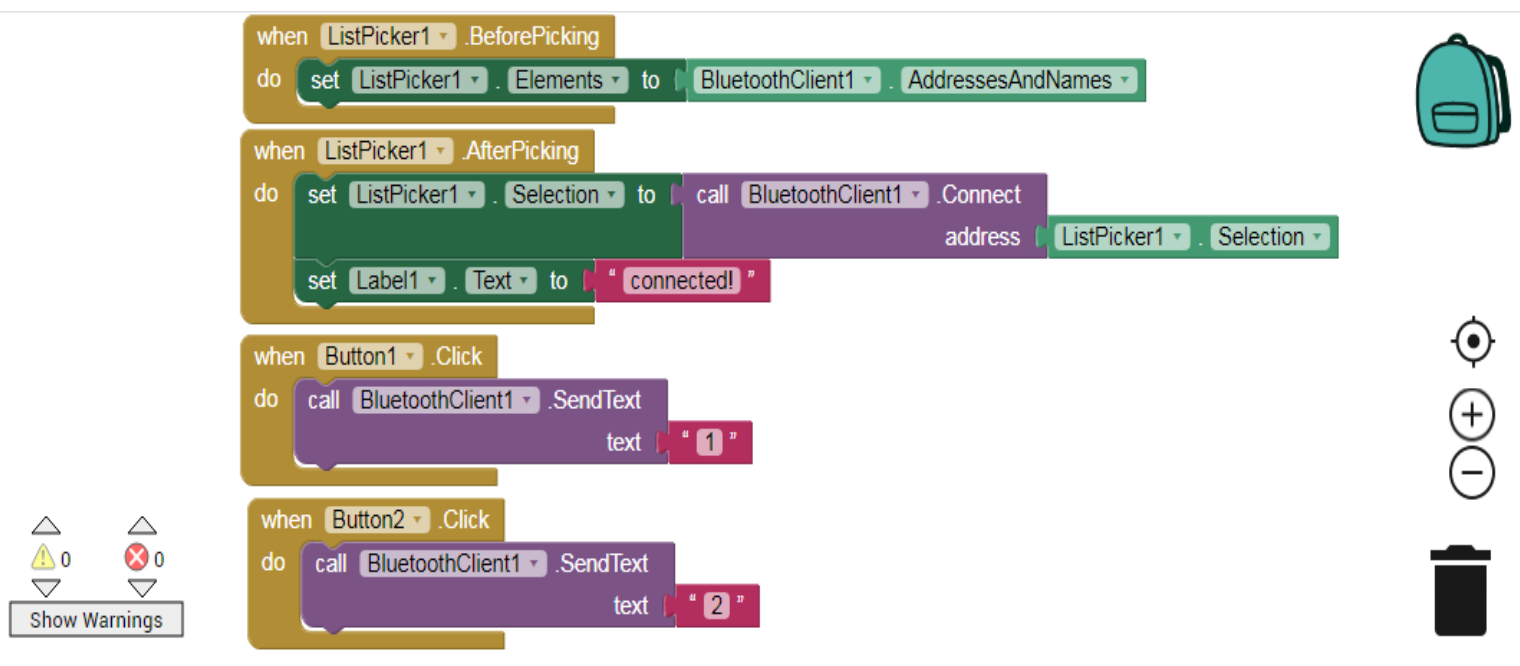

(a)

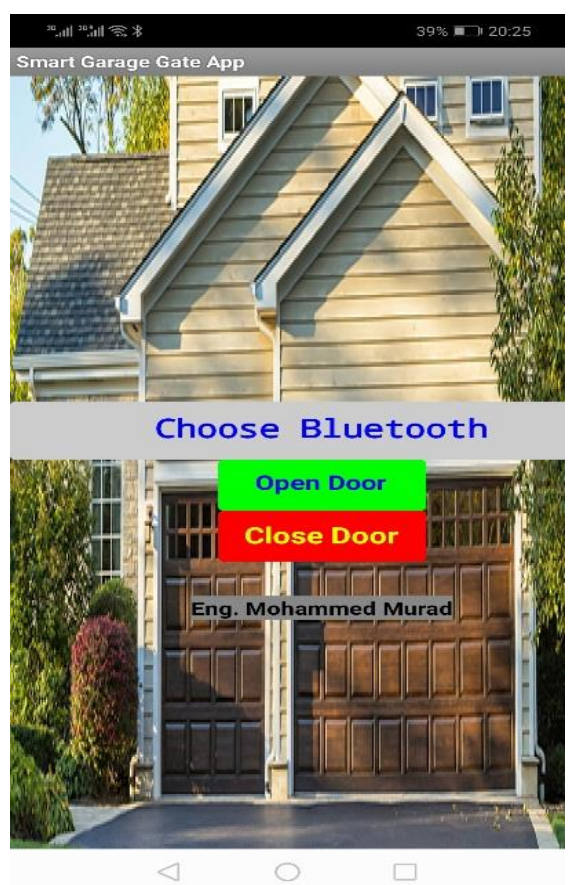

(b)

Figure 12. (a) The graphical blocks of the programed app for the garage gate and (b) The programmed app inside the Huawei smart mobile phone 
Figures 13-16; respectively, illustrates the block diagram of the power supply control, the block diagram of the security part, the block diagram of the automation and control part for the proposed system, and the implemented system for the smart home.

Table 1. The task of each sensor in the automation part

\begin{tabular}{cc}
\hline Sensor & Task \\
\hline Flame sensor & Detect the fire \\
Gas sensor \#1 & Detect the leakage of the LPG \\
Gas sensor \#2 & Detect the unwanted smell in the toilet \\
Temperature sensor & Monitoring the room temperature \\
Soil moisture sensor & Monitoring the soil moisture level \\
Water level sensor & Monitoring the tank water level \\
\hline
\end{tabular}

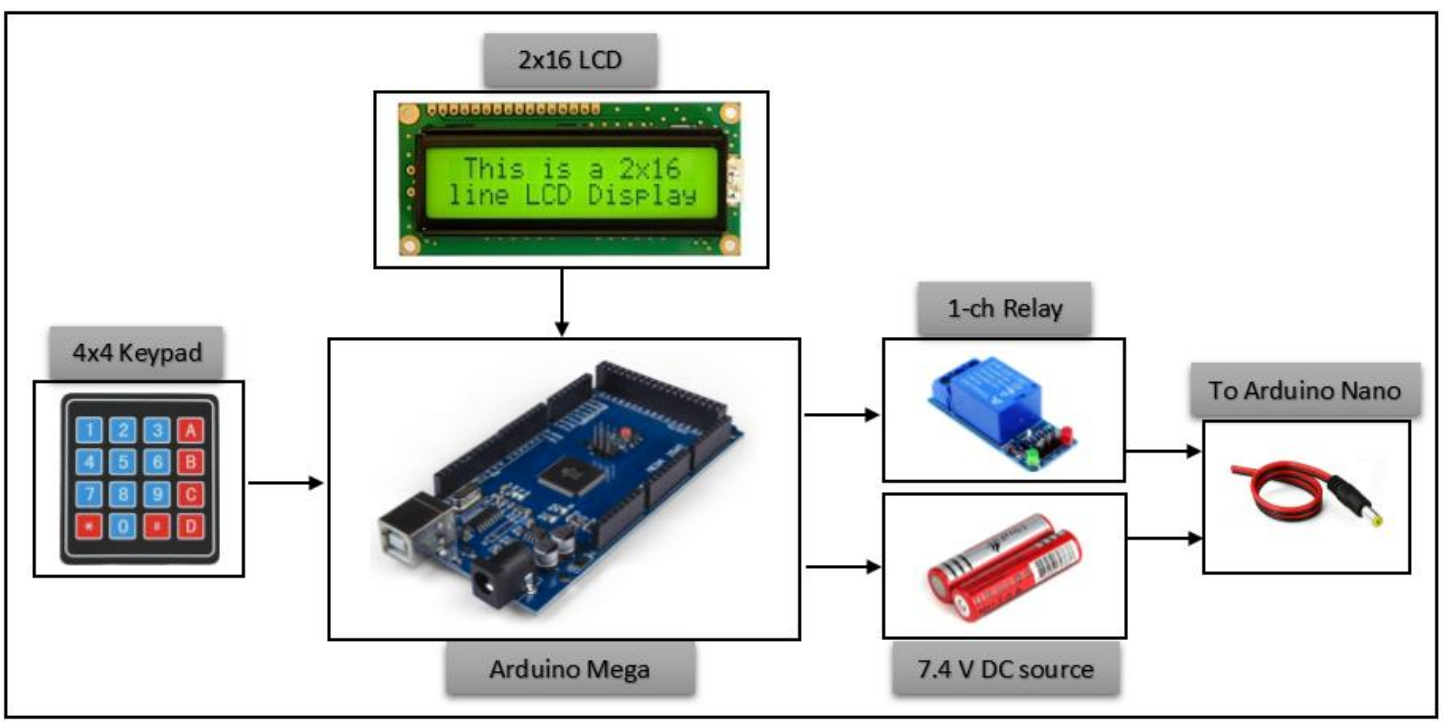

Figure 13. Block diagram of the control circuit for the power feeding

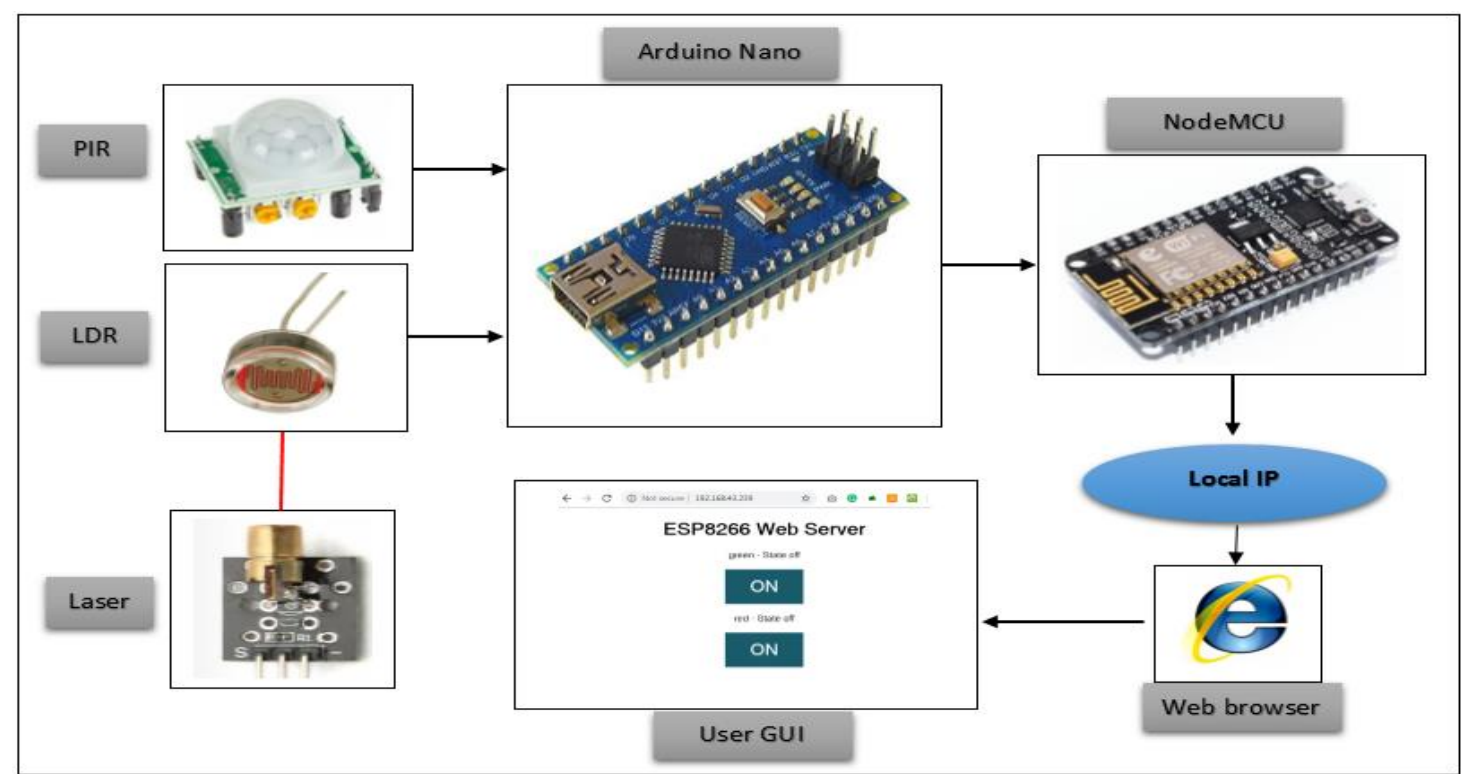

Figure 14. Block diagram for the security part of the proposed system 


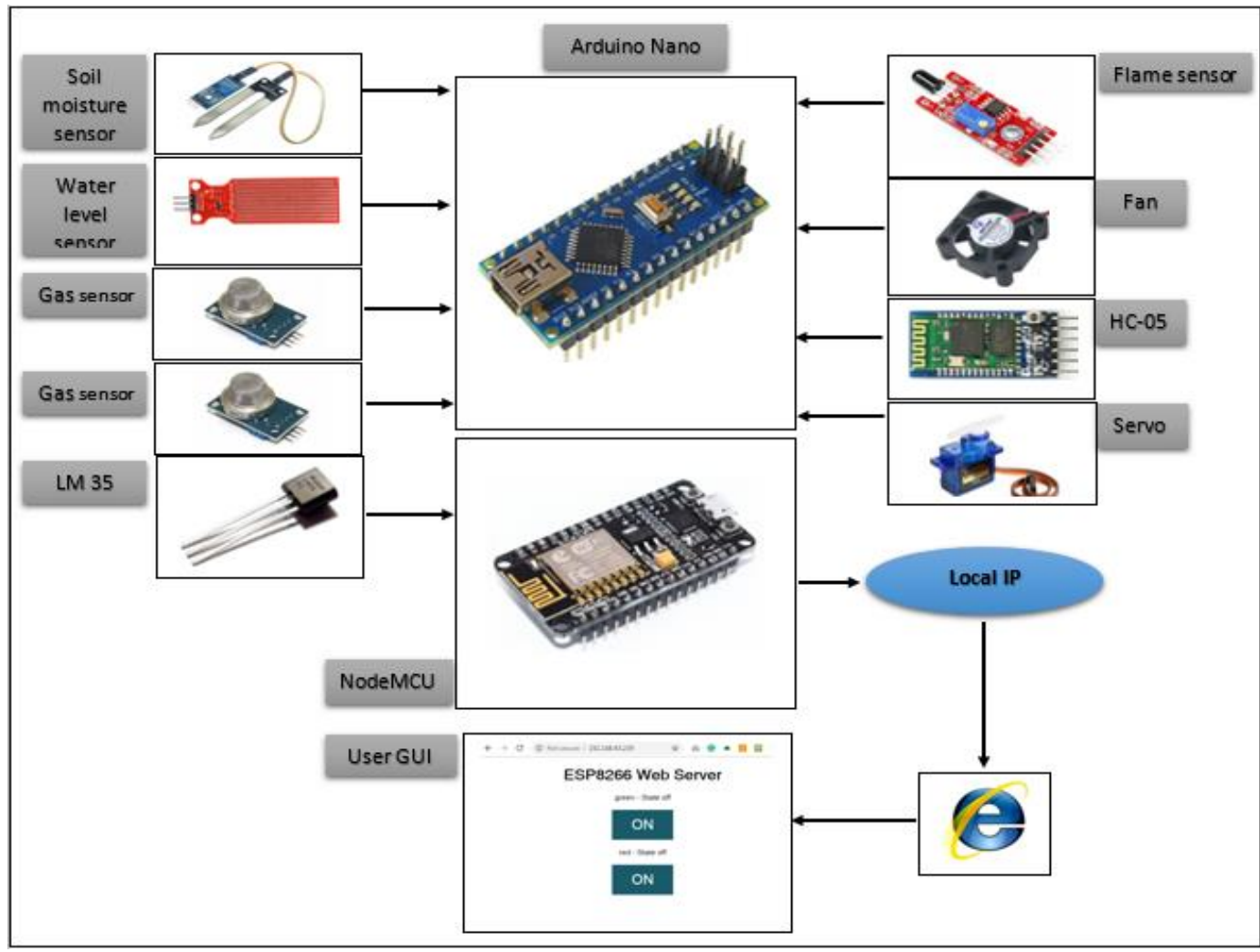

Figure 15. Block diagram for the automation and control part of the proposed system

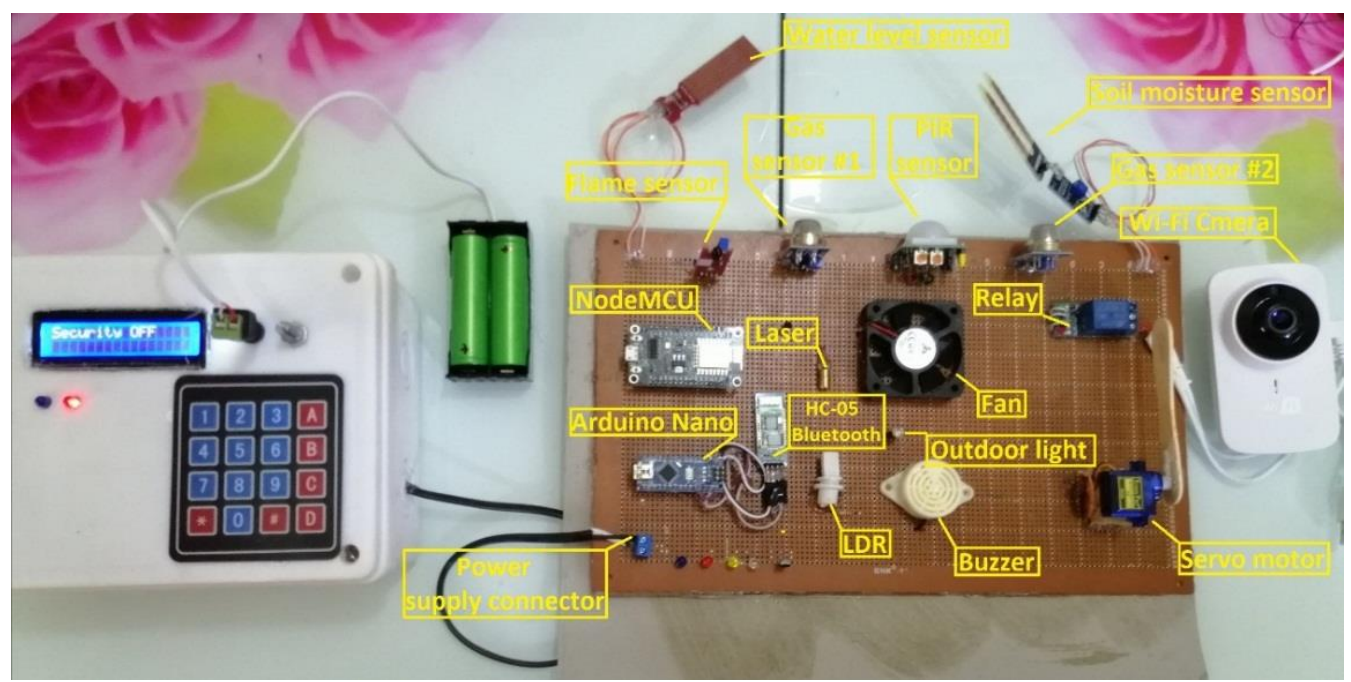

Figure 16. The implemented smart home and security system

\subsection{Results and Discussion}

Several steps must be taken in order to operate and test the proposed smart home system, the first of which is the entering of the $\mathrm{ON}$ state password for the operation of the system power supply circuit, as shown in Figure 17. Thereafter, a connection should be established between the NodeMCU microcontroller and the Internet via the Wi-Fi. The last one is the wireless connection between the Android smartphone and the Arduino Bluetooth to test the remotely opening/closing of the garage gate through the programmed app (Figure 12-b). Several methods are utilised to test the work and performance of system sensors, as demonstrated in Table 2. 


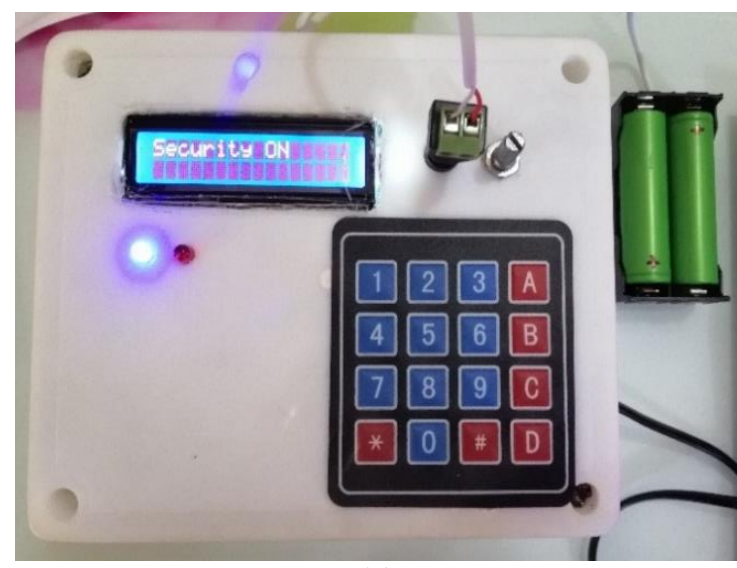

(a)

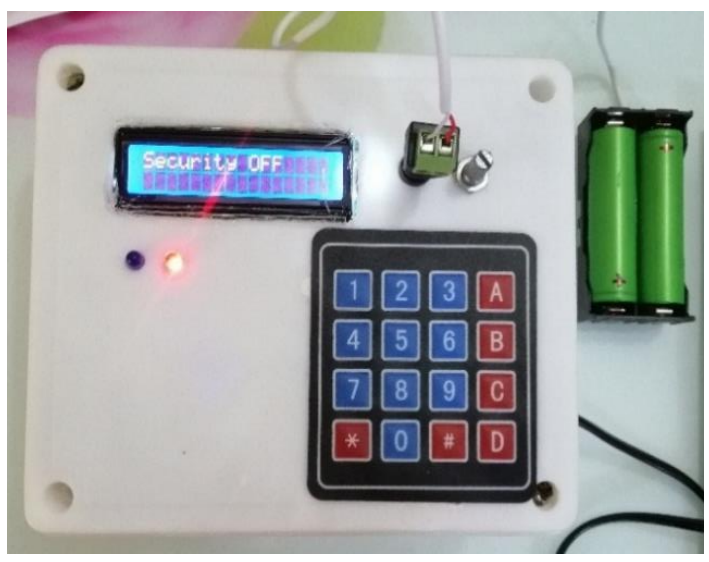

(b)

Figure 17. (a) The activation of the power supply circuit and (b) The deactivation of the power supply circuit

Table 2. The practical test procedure for the system sensors

\begin{tabular}{cl}
\hline Sensor & Test \\
\hline Flame & $\begin{array}{l}\text { The performance of the sensor was examined by placing a fire source, such as a lighter near the sensor, after } \\
\text { which the Arduino Nano switches ON the LED that represents the water pump and sends logic " } 1 \text { " to the } \\
\text { NodeMCU in order to display the warning message on the GUI } \\
\text { The performance of the sensor was examined by placing a liquid gas source such as the one in the lighter near } \\
\text { the sensor, after which the Arduino Nano sends a logic "1" to the NodeMCU in order to display a warning } \\
\text { message on the GUI } \\
\text { The sensor was tested by placing a heat source near it, after that the NodeMCU activates the cooling systems } \\
\text { represented by the LED and displays the temperature value on the GUI } \\
\text { The sensor was tested by passing in front of it, then Arduino Nano activates the alarm, Wi-Fi camera, and } \\
\text { Temperature } \\
\text { PIR } \\
\text { The sensor was tested by putting it in a small container filled with water, then the Arduino operates the water } \\
\text { pump represented by the LED, and the same procedure is utilised to test the soil moisture sensor }\end{array}$ \\
\hline
\end{tabular}

Figure 18 respectively, illustrate the messages appeared on the GUI in the case of fire detection, gas leak detection, motion detection, and the safe mode case. Figure 19 presents the implemented system during the ON-turning operation.

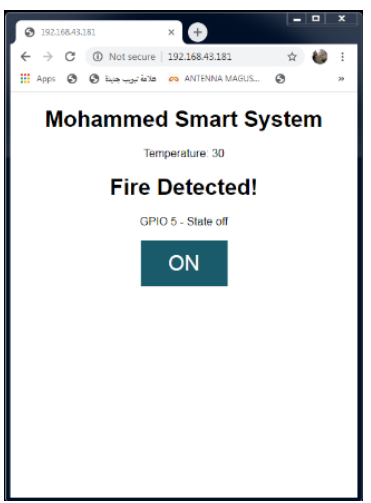

(a)

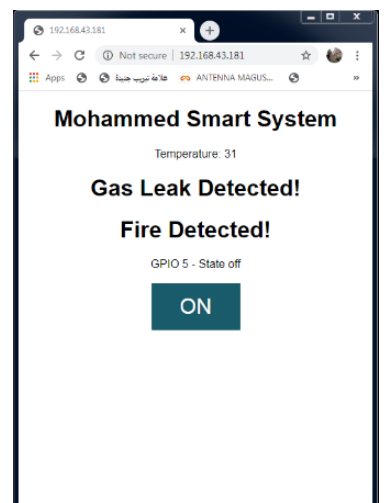

(b)

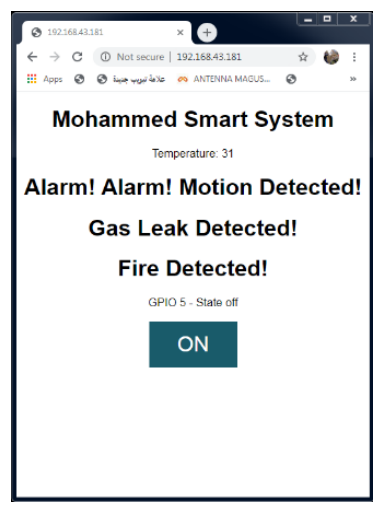

(c)

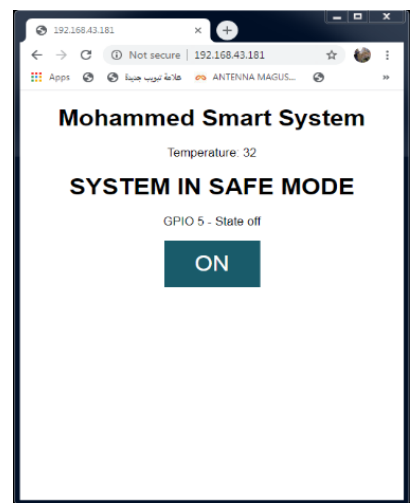

(d)

Figure 18. Appeared messages on the GUI in the case of: (a) Fire detection, (b) Gas leak detection, (c) Motion detection, and (e) Safe mode 


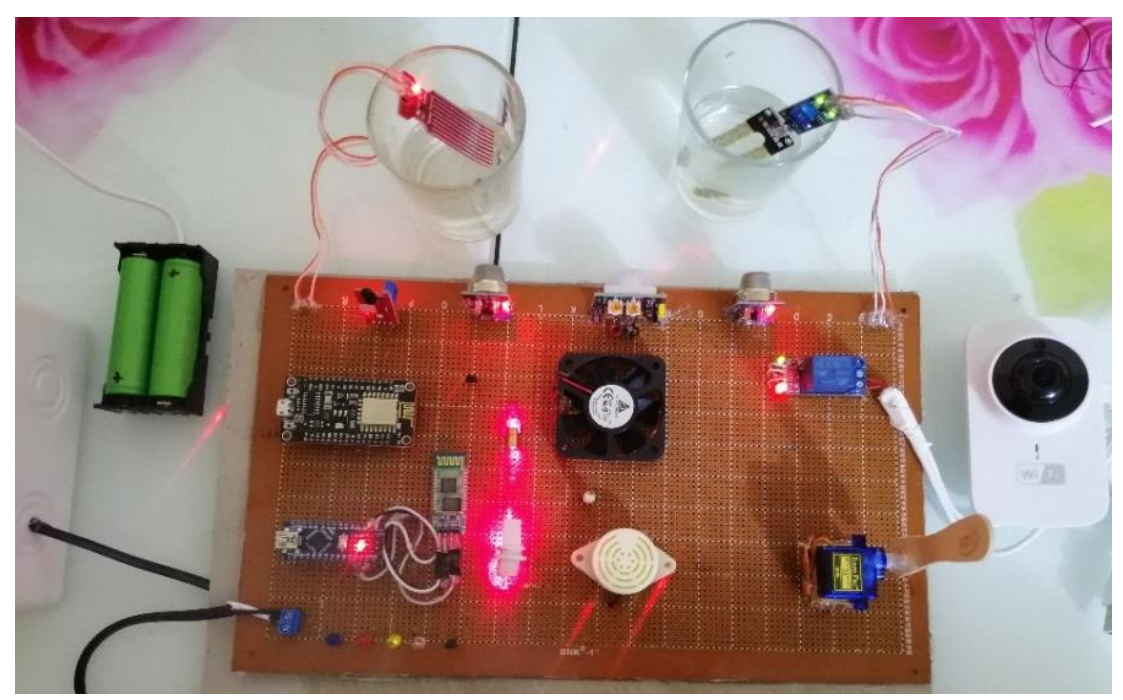

Figure 19. The implemented system during the practical test

\section{CONCLUSION}

This paper investigates the concept of IoT-based smart home and automation systems. This paper proposes the design of smart home based on Arduino and NodeMCU microcontrollers. The designed system was included a smart garage gate that is remotely controlled by a smart mobile phone, two levels of security to protect the home from theft, as well as an automation and control system to delivers the best performance. Security and automation parts were linked to the IoT technology which supported by the NodeMCU microcontroller. The NodeMCU was programmed through the Arduino IDE to create a GUI that is accessed via the granted local IP address from the NodeMCU, thus facilitates the process of the home monitoring wirelessly. The implemented system was tested practically and good performance has been achieved.

\section{REFERENCES}

[1] T. S. Gunawan, I. Rahmithul, H. Yaldi, M. Kartiwi, and H. Mansor, "Performance evaluation of smart home system using internet of things," International Journal of Electrical and Computer Engineering (IJECE), vol. 8, no. 1, pp. 400-411, 2018.

[2] A. N. Azlina, A. B. Zanariah, and Y. Faridah, "Intelligent home automated system," Indonesian Journal of Electrical Engineering and Computer Science (IJEECS), vol. 15, no. 2, pp. 733-742, 2019.

[3] S. M. R. Islam, D. Kwak, and H. Kabir, "The internet of things for health care : A comprehensive survey," IEEE Access, vol. 3, pp. 678-708, 2015.

[4] H. Truong and S. Dustdar, "Principles for engineering IoT cloud systems," IEEE CLOUD COMPUTING, vol. 2, no. 2, pp. 68-76, 2015.

[5] M. Burhan, R. A. Rehman, B.-S. Kim, and B. Khan, "IoT elements, layered architectures and security," sensors, vol. 18 , no. 9, pp. 1-37, 2018.

[6] Keramidas, Georgios, Nikolaos Voros, and Michael Hübner, Components and Services for IoT Platforms, Springer International $\mathrm{Pu}, 2016$.

[7] H. M. Marhoon and I. A. Taha, "Design and implementation of intelligent circuit breaker for electrical current sensing and monitoring," Int. J. Core Eng. Manag., vol. 4, no. 11, pp. 39-49, 2018.

[8] O. Chamorro-atalaya and D. Arce-santillan, "Fire alert system through text messages, with arduino mega technology and GSM SIM 900 module," Indonesian Journal of Electrical Engineering and Computer Science (IJEECS), vol. 18, no. 3, pp. 1215-1221, 2020.

[9] O. K. Mohammed, O. Bayat, and H. M. Marhoon, "Design and implementation of integrated security and safety system based on internet of things," Int. J. Eng. Technol., vol. 7, no. 4, pp. 5705-5711, 2019.

[10] S. M. Ahmed, H. M. Marhoon, and O. Nuri, "Implementation of smart anti - theft car security system based on GSM,” Int. J. Eng. Technol., vol. 7, no. 4, pp. 5261-5265, 2018.

[11] I. Tazi, K. Triyana, and D. Siswanta, "A novel Arduino Mega 2560 microcontroller- based electronic tongue for dairy product classification," in AIP Conference Proceedings, vol. 1755, no. 12016, pp. 1-5, 2016.

[12] H. M. Marhoon, Z. A. Karam, and A. M. Al-kadhimi, "Implementation of cell phone detection mobile robot for restricted areas using nodemcu," Iraqi J. Inf. Commun. Technol., vol. 1, no. 1, pp. 27-35, 2018.

[13] A. H. Ali, A. H. Duhis, N. Aad, L. Alzurfi, and M. J. Mnati, "Smart monitoring system for pressure regulator based on IoT," International Journal of Electrical and Computer Engineering (IJECE), vol. 9, no. 5, pp. 3450-3456, 2019. 
[14] M. U. Harun, A. Rasyid, S. Sukaridhoto, M. I. Dzulqornain, and A. Rifa, "Integration of IoT and chatbot for aquaculture with natural language processing," TELKOMNIKA (Telecommunication, Computing, Electronics and Control), vol. 18, no. 2, pp. 640-648, 2020.

[15] I. A. Taha and H. M. Marhoon, "Implementation of controlled robot for fire detection and extinguish to closed areas based on arduino," TELKOMNIKA (Telecommunication, Computing, Electronics and Control), vol. 16, no. 2, pp. 654-664, 2018.

[16] F. Idris, N. Hashim, A. Fauzankadmin, and L. B. Yee, "Intelligent fire detection and alert system using labVIEW," International Journal of Electrical and Computer Engineering (IJECE), vol. 9, no. 3, pp. 1842-1849, 2019.

[17] H. M. Marhoon, M. I. Mahdi, E. D. Hussein, and A. R. Ibrahim, "Designing and implementing applications of smart home appliances," Mod. Appl. Sci., vol. 12, no. 12, pp. 8-17, 2018.

[18] S. S. Sarnin, et al., "Smart insects repeller," Indonesian Journal of Electrical Engineering and Computer Science (IJEECS), vol. 17, no. 1, pp. 205-212, 2020.

[19] A. Murad, O. BAYAT, and H. M. Marhoon, "Implementation of rover tank firefighting robot for closed areas based on arduino microcontroller," Indonesian Journal of Electrical Engineering and Computer Science (IJEECS), vol.21, no.1, 2021.

[20] Z. H. C. Soh, S. A. C. Abdullah, and M. A. Shafie, "Home and industrial safety IoT on LPG gas leakage detection and alert system," Int. J. Adv. Soft Compu. Appl, vol. 11, no. 1, pp. 131-145, 2019.

[21] V. Suma, R. R. Shekar and K. A. Akshay, "Gas leakage detection based on IoT," 2019 3rd International conference on Electronics, Communication and Aerospace Technology (ICECA), IEEE, India, pp. 1312-1315, 2019.

[22] A. Popa et al., "An intelligent IoT-based food quality monitoring approach using low-cost sensors," Symmetry, vol. 11, no. 3, pp. 1-18, 2019.

[23] E. I. Agustin, R. T. Yunardi, and A. A. Firdaus, "Voice recognition system for controlling electrical appliances in smart hospital room," TELKOMNIKA (Telecommunication, Computing, Electronics and Control), vol. 17, no. 2, pp. 965-972, 2019.

[24] M. Nur, A. Mohd, S. A. Jumaat, C. Rimong, and A. Jawa, "Dual axis solar tracker with IoT monitoring system using arduino," International Journal of Power Electronics and Drive Systems (IJPEDS), vol. 11, no. 1, pp. 451-458, 2020.

[25] R. M. Ramli et al., "Development of robotic rover with controller \& vision system," Indonesian Journal of Electrical Engineering and Computer Science (IJEECS), vol. 18, no. 2, pp. 766-773, 2020. 